\title{
Prevention of Cannabinoid Withdrawal Syndrome by Lithium: Involvement of Oxytocinergic Neuronal Activation
}

\author{
Shu-Sen Cui,, ${ }^{1}$ Rudy C. Bowen, ${ }^{1}$ Gui-Bao Gu, ${ }^{2}$ Darren K. Hannesson, ${ }^{1}$ Peter H. Yu, ${ }^{1}$ and Xia Zhang ${ }^{1}$ \\ ${ }^{1}$ Neuropsychiatry Research Unit, Department of Psychiatry, University of Saskatchewan, Saskatoon, Saskatchewan, \\ Canada S7N 5E4, and '2Division of Neurobiology, Department of Neurology and Neuroscience, Weill Medical College of \\ Cornell University, New York, New York 10021
}

Cannabis (i.e., marijuana and cannabinoids) is the most commonly used illicit drug in developed countries, and the lifetime prevalence of marijuana dependence is the highest of all illicit drugs in the United States. To provide clues for finding effective pharmacological treatment for cannabis-dependent patients, we examined the effects and possible mechanism of lithium administration on the cannabinoid withdrawal syndrome in rats.

A systemic injection of the mood stabilizer lithium, at serum levels that were clinically relevant, prevented the cannabinoid withdrawal syndrome. The effects of lithium were accompanied by expression of the cellular activation marker Fos proteins within most oxytocin-immunoreactive neurons and a significant increase in oxytocin mRNA expression in the hypothalamic paraventricular and supraoptic nuclei. Lithium also produced a significant elevation of oxytocin levels in the peripheral blood.
We suggest that the effects of lithium against the cannabinoid withdrawal syndrome are mediated by oxytocinergic neuronal activation and subsequent release and action of oxytocin within the CNS. In support of our hypothesis, we found that the effects of lithium against the cannabinoid withdrawal syndrome were antagonized by systemic preapplication of an oxytocin antagonist and mimicked by systemic or intracerebroventricular injection of oxytocin.

These results demonstrate that oxytocinergic neuronal activation plays a critical role in the action of lithium against the cannabinoid withdrawal syndrome in rats, thus providing a potentially novel strategy for the treatment of cannabis dependence in humans.

Key words: cannabis; marijuana; cannabinoid; withdrawal syndrome; lithium; oxytocin
Cannabis (i.e., marijuana, hashish, and cannabinoids) has been the most commonly used illicit drug in developed countries over several decades (Grinspoon and Bakalar, 1992; Donnelly and Hall, 1994; Budney et al., 1999), and the lifetime prevalence of marijuana dependence is the highest of all illicit drugs in the United States (Substance Abuse and Mental Health Services Administration, 1996; Kandel et al., 1997). Animal studies have shown that cannabinoids act on the same neural substrates as and have similar effects to the addictive substances nicotine, alcohol, cocaine, and heroin (De Fonseca et al., 1997; Tanda et al., 1997; Ledent et al., 1999). Human studies have demonstrated that a significant subset of chronic cannabis users have difficulty quitting cannabis use and consistently exhibit a cluster of symptoms after abrupt cessation of cannabis use (Cottler et al., 1995; Wiesbeck et al., 1996; Budney et al., 1998; Haney et al., 1999a,b; Kouri and Pope, 2000), including irritability, sleep difficulties, restlessness, anxiety, depression, stomach pain, and reduced appetite. Many chronic cannabis users report an average of 6.4 withdrawal symptoms of at least moderate severity (Budney et al., 1999), a number

Received July 18, 2001; revised Sept. 21. 2001; accepted Sept. 30, 2001.

This work was supported by a Health Services Utilization and Research Commission (HSURC) (Saskatchewan, Canada) establishment grant and Canadian Institutes of Health Research operating grant (to X.Z.), as well as by an HSURC postdoctoral fellowship award (to S.S.C.). We thank Dr. R. Mechoulam for providing some HU210, Dr. R. Freibinger (Merck, Rahway, NJ) for providing L-368,899, and Y. Li and H. Liu for technical assistance.

Correspondence should be addressed to Dr. Xia Zhang, Neuropsychiatry Research Unit, Department of Psychiatry, University of Saskatchewan, A114 Medical Research Building, 103 Wiggins Road, Saskatoon, Saskatchewan, Canada S7N 5E4. E-mail: zhangxia@duke.usask.ca.

Copyright (ㄷ) 2001 Society for Neuroscience $\quad 0270-6474 / 01 / 219867-10 \$ 15.00 / 0$ that exceeds the criteria for DSM-IV substance-withdrawal disorders (i.e., 2-4) (American Psychiatry Association, 1994).

Despite this, there are no effective long-term treatments for cannabis dependence (Budney et al., 1997, 1998; McLellan et al., 2000). Recently, Stephens et al. (1993, 1994) have performed a controlled study on treating marijuana dependence in humans using cognitive-behavioral and social approaches. This therapy produced relatively good short-term results, but long-term relapse rates were high, suggesting that cannabis dependence can be quite intractable.

Because the degree of physical dependence to an illicit drug is characterized by the severity of withdrawal reactions, we determined to find a new agent for treating the cannabinoid withdrawal syndrome in rats to provide clues for finding effective medication to treat cannabis-dependence in patients. We initially questioned whether lithium might inhibit some of the cannabis withdrawal symptoms (i.e., irritability, anxiety, and depression), because these symptoms often accompany mood disorders, and lithium is the most commonly used mood stabilizer for treating bipolar mood disorder (Manji et al., 1995). To test this hypothesis, we had performed a pilot experiment to explore the effects of lithium on the cannabinoid withdrawal syndrome in a rat model. The model was established by injecting the competitive cannabinoid antagonist AM281 to rats treated daily with the synthetic cannabinoid agonist HU210 (De Fonseca et al., 1997; Ledent et al., 1999). Unexpectedly, our preliminary results showed that a systemic injection of lithium chloride blocked all the withdrawal symptoms tested and produced Fos expression in many brain regions, including hypothalamic areas that contain oxytocin. Therefore, we designed the present study to examine the effects 


\begin{tabular}{|c|c|c|c|c|c|c|c|}
\hline Group & $5.5 \mathrm{~d}$ & $4 \mathrm{hr}$ & & & & & \\
\hline 1 & Twice daily HU210 & $\rightarrow$ & AM281 & & & & \\
\hline 2 & Twice daily vehicle & $\rightarrow$ & AM281 & & & & \\
\hline 3 & Twice daily vehicle & $\rightarrow$ & Lithium (8 meq/kg) & & & & \\
\hline \multirow[t]{2}{*}{4} & Twice daily HU210 & $\rightarrow$ & Vehicle & & & & \\
\hline & $5.5 \mathrm{~d}$ & $3 \mathrm{hr}+45 \mathrm{~min}$ & & $15 \mathrm{~min}$ & & & \\
\hline 5 & Twice daily HU210 & $\rightarrow$ & Vehicle & $\rightarrow$ & AM281 & & \\
\hline 6 & Twice daily HU210 & $\rightarrow$ & Lithium (1 meq/kg) & $\rightarrow$ & AM281 & & \\
\hline 7 & Twice daily HU210 & $\rightarrow$ & Lithium (2 meq $/ \mathrm{kg})$ & $\rightarrow$ & AM281 & & \\
\hline 8 & Twice daily HU210 & $\rightarrow$ & Lithium (4 meq/kg) & $\rightarrow$ & AM281 & & \\
\hline 9 & Twice daily HU210 & $\rightarrow$ & Lithium (8 meq/kg) & $\rightarrow$ & AM281 & & \\
\hline 10 & Twice daily HU210 & $\rightarrow$ & Lithium $(16 \mathrm{meq} / \mathrm{kg})$ & $\rightarrow$ & AM281 & & \\
\hline 11 & Twice daily vehicle & $\rightarrow$ & Lithium (4 meq/kg) & $\rightarrow$ & vehicle & & \\
\hline \multirow[t]{2}{*}{12} & Twice daily vehicle & $\rightarrow$ & Vehicle & $\rightarrow$ & vehicle & & \\
\hline & $5.5 \mathrm{~d}$ & $3 \mathrm{hr}+55 \mathrm{~min}$ & & $5 \min$ & & & \\
\hline \multirow[t]{2}{*}{13} & Twice daily HU210 & $\rightarrow$ & Lithium (4 meq/kg) & $\rightarrow$ & AM281 & & \\
\hline & $5.5 \mathrm{~d}$ & $3 \mathrm{hr}+30 \mathrm{~min}$ & & $15 \mathrm{~min}$ & & $15 \mathrm{~min}$ & \\
\hline 14 & Twice daily HU210 & $\rightarrow$ & L-368,899 & $\rightarrow$ & $\begin{array}{l}\text { Lith- } \\
\text { ium } \\
\text { Lith- }\end{array}$ & $\rightarrow$ & AM281 \\
\hline 15 & Twice daily HU210 & $\rightarrow$ & Vehicle & $\rightarrow$ & ium & $\rightarrow$ & AM281 \\
\hline 16 & Twice daily HU210 & $\rightarrow$ & L-368,899 & $\rightarrow$ & Vehicle & $\rightarrow$ & AM281 \\
\hline 17 & Twice daily HU210 & $\rightarrow$ & Vehicle & $\rightarrow$ & Vehicle & $\rightarrow$ & AM281 \\
\hline 18 & $\begin{array}{l}\text { Twice daily vehicle } \\
5.5 \mathrm{~d}\end{array}$ & $\overrightarrow{3 \mathrm{hr}}+45 \mathrm{~min}$ & L-368,899 & $\overrightarrow{15} \mathrm{~min}$ & Vehicle & $\rightarrow$ & Vehicle \\
\hline 19 & Twice daily HU210 & $\rightarrow$ & $\begin{array}{l}\text { Oxytocin } \\
\text { Oxytocin fragment }\end{array}$ & $\rightarrow$ & AM281 & & \\
\hline 20 & Twice daily HU210 & $\rightarrow$ & $4-9$ & $\rightarrow$ & AM281 & & \\
\hline \multirow[t]{2}{*}{21} & Twice daily HU210 & $\rightarrow$ & Vehicle & $\rightarrow$ & AM281 & & \\
\hline & & $10 \mathrm{~d}$ & $5.5 \mathrm{~d}$ & $\begin{array}{l}3 \mathrm{hr}+ \\
45 \mathrm{~min}\end{array}$ & & $15 \mathrm{~min}$ & \\
\hline 22 & Surgery & $\rightarrow$ & Twice daily HU210 & $\rightarrow$ & $\begin{array}{l}\text { Oxyto- } \\
\text { cin }\end{array}$ & $\rightarrow$ & AM281 \\
\hline 23 & Surgery & $\rightarrow$ & Twice daily HU210 & $\rightarrow$ & Vehicle & $\rightarrow$ & AM281 \\
\hline
\end{tabular}

See Materials and Methods for detailed description.

and possible mechanism of lithium treatment for the cannabinoid withdrawal syndrome in rats.

\section{MATERIALS AND METHODS}

Animals. Adult male Long-Evans rats weighing 250-300 gm were used in all the experiments. The animals were housed under controlled temperature and light conditions (12 hr light/dark cycle with lights on at 8:00 A.M.), with ad libitum access to food and water. All procedures were in accordance with the guidelines established by the Canadian Council on Animal Care as approved by the University of Saskatchewan Animal Care Committee.

Animal treatment for behavioral observation. To establish the cannabinoid withdrawal model, the group 1 rats received twice daily injections of HU210 (100 $\mu \mathrm{g} / \mathrm{kg}$, i.p., dissolved in DMSO; Tocris Cookson, Ballwin, MO) for $5 \mathrm{~d}$. On day 6 , they received a morning injection of HU210 followed $4 \mathrm{hr}$ later by an AM281 injection $(3 \mathrm{mg} / \mathrm{kg}$, i.p., dissolved in DMSO; Tocris) (Table 1) to precipitate the cannabinoid withdrawal syndrome (Ledent et al., 1999). Three control groups of rats received twice daily injections of vehicle (groups 2 and 3) or HU210 (group 4) for $5.5 \mathrm{~d}$, followed $4 \mathrm{hr}$ later by an injection of AM281 (group 2), lithium chloride (8 meq/kg; Sigma, St. Louis, MO) (group 3), or vehicle (group 4) (Table 1).

The effects of lithium on the cannabinoid withdrawal syndrome were examined by injecting saline or five doses of lithium chloride $(1,2,4,8$, and $16 \mathrm{meq} / \mathrm{kg}$, dissolved in physiological saline; Sigma) $15 \mathrm{~min}$ before AM281 injection to rats that had received twice daily injections of HU210 for 5.5 d (Table 1, groups 5-10). An additional two control groups of rats that had received twice daily injections of vehicle for $5.5 \mathrm{~d}$ were given lithium (4 meq/kg) (group 11) or saline injection (group 12) $15 \mathrm{~min}$ before vehicle administration. The group 13 rats that had received twice daily injections of HU210 for 5.5 d received lithium (4 $\mathrm{meq} / \mathrm{kg}$ ) $5 \mathrm{~min}$ before AM281 injection (Table 1).

To study the effects of the oxytocin receptor antagonist L-368,899 (Merck, Rahway, NJ) on the action of lithium on the cannabinoid withdrawal syndrome, one group of rats treated twice daily with HU210 for $5.5 \mathrm{~d}$ was sequentially injected with, at 15 min intervals, L-368,899 (5 $\mathrm{mg} / \mathrm{kg}$, i.p., dissolved in physiological saline), lithium (4 meq $/ \mathrm{kg})$, and AM281 (Table 1, group 14). Four control groups of rats (Table 1, groups 15-18) received similar treatment, with vehicle injection in the place of L-368,899 in group 15, vehicle injection in the place of lithium injection in group 16, vehicle injections in the places of L-368,899 and lithium in group 17, and vehicle injection in the places of HU210, lithium, and AM281 injections in group 18.

The effects of oxytocin on the cannabinoid withdrawal syndrome were examined by using two protocols: (1) after twice daily HU210 injections for $5.5 \mathrm{~d}$, rats received oxytocin $(200 \mu \mathrm{g} / \mathrm{kg}$, s.c., dissolved in physiological saline; Sigma), oxytocin fragment 4-9 (2 $\mu \mathrm{g} / \mathrm{kg}$, s.c., dissolved in physiological saline; Genemed Synthesis Inc., San Francisco, CA) or 
saline injection 15 min before AM281 precipitation (Table 1, groups 19-21); (2) under anesthesia each rat received implantation of a guide cannula into the lateral brain ventricle, followed sequentially by $10 \mathrm{~d}$ recovery, twice daily HU210 injection for $5.5 \mathrm{~d}$, and an oxytocin (2 $\mu \mathrm{g} / \mathrm{kg}$ ) or vehicle injection through the guide cannula $15 \mathrm{~min}$ before AM281 precipitation (Table 1, groups 22, 23). The $200 \mu \mathrm{g} / \mathrm{kg}$ dose of systemic oxytocin injection was chosen according to previous studies showing that this dose of systemic oxytocin produced significant suppression effects on opiate dependence and cocaine tolerance (Kovacs et al., 1998; Sarnyai, 1998). The 15 min interval between oxytocin and AM281 injections was chosen to be consistent with the lithium injection procedure.

Measurement of plasma concentrations of lithium. Clinically, the plasma levels of lithium in patients are measured $12 \mathrm{hr}$ after the last dose (Jefferson, 1987). To provide clinically relevant information, we measured plasma lithium levels in five groups of rats that had received twice daily injections of lithium chloride at $1,2,4,8,16 \mathrm{meq} / \mathrm{kg}$ doses $15 \mathrm{~min}$ before each HU210 injection $(100 \mu \mathrm{g} / \mathrm{kg}$, i.p.) for $5 \mathrm{~d}$. Control group received vehicle instead of lithium. Rats were decapitated $12 \mathrm{hr}$ after the last lithium or vehicle injection. Blood was collected and centrifuged. Plasma lithium concentrations were measured by using an atomic absorption spectrophotometer.

Immunocytochemistry. To explore the mechanism underlying lithium treatment for the cannabinoid withdrawal syndrome, we examined the anatomical distribution of Fos immunoreactivity in the brain, which has been widely used as a sensitive, nonspecific marker for visualizing neuronal activation after various stimuli (Morgan and Curran, 1991; Zhang et al., 1991, 1997b). Groups of rats were given different treatments: an acute injection of five doses of lithium chloride $(1,2,4,8$, and $16 \mathrm{meq} / \mathrm{kg}$, i.p.); twice daily HU210 injections, followed by AM281 precipitation; twice daily HU210 injections; a single injection of AM281 (3 mg/kg, i.p.), or saline. In addition, rats in the above groups 5, 8, 11, and 12 (Table 1) were also used for Fos immunohistochemistry. Three hours after the last treatment, rats were deeply anesthetized with sodium pentobarbital (100 $\mathrm{mg} / \mathrm{kg}$, i.p.) and perfused transcardially first with $150 \mathrm{ml}$ of $0.1 \mathrm{M}$ PBS, $\mathrm{pH} 7.4$, and then with $250 \mathrm{ml}$ of freshly prepared $4 \%$ paraformaldehyde in PBS. The brains were immediately removed, post-fixed for $2 \mathrm{hr}$ in the same fixative, and immersed in $30 \%$ sucrose dissolved in PBS at $4^{\circ} \mathrm{C}$ for 2-3 d. Fourty-micrometer-thick sections were cut on a sliding microtome in the frontal plane and collected through the olfactory bulbs and forebrain to the hindbrain. The brain sections were divided into several series: two series of sections were stored in a cryoprotectant at $-20^{\circ} \mathrm{C}$ for later use; one series was stained for cresyl violet to facilitate the identification of specific brain nuclei; and another series was processed for Fos immunocytochemistry using a conventional avidin-biotin-immunoperoxidase technique as previously described (Zhang et al., 1991, 1997a, 2001).

Briefly, this procedure included pretreating sections at room temperature for $30 \mathrm{~min}$ in $0.2 \%$ hydrogen peroxide and for $1 \mathrm{hr}$ in the blocking buffer containing PBS, $0.3 \%$ Triton X-100, and 5\% normal goat serum. Sections were then incubated in the primary rabbit anti-Fos antibody $\left(1: 40,000\right.$; Sigma), diluted in the blocking buffer at $4^{\circ} \mathrm{C}$ for $3 \mathrm{~d}$ on a shaker. The primary antibody was localized using Vectastain Elite reagents (Vector Laboratories, Burlingame, CA), namely, sections were incubated sequentially in biotinylated goat anti-rabbit $\operatorname{IgG}(1: 250)$ and avidin-biotinylated horseradish peroxidase complex (1:100) for $2 \mathrm{hr}$ at each incubation. The reaction product was developed by incubating the sections in a solution containing diaminobenzidine and hydrogen peroxide at room temperature for $\sim 2 \mathrm{~min}$. The sections were mounted onto glass slides, which were then air-dried, dehydrated, cleared, and coverslipped with DPX.

To examine whether Fos protein expression in those hypothalamic areas that contain oxytocin occurred in the oxytocinergic neurons, Fos and oxytocin double immunofluorescent staining was performed in one series of sections that had been stored at $-20^{\circ} \mathrm{C}$, according to procedures described elsewhere (Gerfen and Sawchenko, 1984). Briefly, the sections were incubated in a mixture of rabbit anti-Fos antibody (1:8000; Sigma) and guinea pig anti-oxytocin antibody (1:1000; Peninsula Laboratories, San Carlos, CA). The antibody mixture was diluted in the blocking buffer containing PBS, $0.3 \%$ Triton $\mathrm{X}-100$, and $2 \%$ normal goat serum, and incubation of this cocktail was performed at $4^{\circ} \mathrm{C}$ for $3 \mathrm{~d}$ on a shaker. After rinses in PBS containing $0.3 \%$ Triton X-100, the sections were incubated in a mixture of affinity-purified secondary antibodies for $2 \mathrm{hr}$ at room temperature: goat anti-rabbit IgG conjugated with Alexa Fluor488 (1:400; Molecular Probes, Eugene, OR) and goat anti-guinea pig
Table 2. Signs of the cannabinoid withdrawal syndrome

\begin{tabular}{ll} 
Counted signs & Observed signs \\
\hline Wet-dog shakes & Piloerection \\
Rearing & Hunting position \\
Forelimb tremor & \\
Penile licking & \\
Mastication & \\
Scratch sequence & \\
\hline
\end{tabular}

IgG conjugated with Alexa Fluor568 (1:400; Molecular Probes). Secondary antibodies were diluted in the blocking buffer. After incubation in secondary antisera, the sections were rinsed and mounted from PBS before being air-dried and coverslipped with buffered glycerol mountant, pH 8.8 .

Immunohistochemical controls were done by omitting primary antibody or by incubating the sections either with normal serum instead of primary antiserum or with antiserum preabsorbed with the immunogen. Sections incubated without primary antibody exhibited virtually no staining, and sections incubated with normal serum showed only nonspecific background staining. Specific staining by Fos and oxytocin was prevented by preabsorption with specific synthetic antigen $(1.0 \mu \mathrm{g} / \mathrm{ml})$.

In situ hybridization. Rats were decapitated $1 \mathrm{hr}$ after the following treatments: saline injection; twice daily HU210 injection for $5.5 \mathrm{~d}$, followed $4 \mathrm{hr}$ later by AM281 precipitation with or without lithium pretreatment $(4 \mathrm{meq} / \mathrm{kg})$; lithium injection $(4 \mathrm{meq} / \mathrm{kg})$; the last twice daily injection of HU210; and an acute AM281 injection. The in situ hybridization procedures used have been described in detail elsewhere (Wisden and Morris, 1994). Briefly, the brains were cut on a cryostat into $10-\mu \mathrm{m}$-thick frontal sections thaw-mounted to coated slides, followed by fixation of the slides with $4 \%$ paraformaldehyde, prehybridization, and stored at $-80^{\circ} \mathrm{C}$ until use. The oligonucleotide probes complimentary to oxytocin bases 247-279 (Ivell and Richter, 1984) were synthesized (Life Technologies, Burlington, Ontario, Canada) and labeled with $\left[\alpha-{ }^{35}\right.$ S $]$ dATP (Boehringer Mannheim, Indianapolis, IN). The sections were incubated in a hybridization buffer containing $50 \%$ formamide (Sigma), $4 \times$ SSC, $10 \%$ dextran sulfate (Sigma), DEPC water, and labeled probes at the concentration of $0.3 \mathrm{pmol} / 5 \mathrm{ml}$. After hybridization overnight at $42^{\circ} \mathrm{C}$, slides were washed in $1 \times \mathrm{SSC}, 0.1 \times \mathrm{SSC}, 70 \%$ ethanol, 95\% ethanol, and then were air-dried and apposed to autoradiography film for $9 \mathrm{hr}$ to obtain x-ray images. Subsequently, slides were dipped in nuclear emulsion, exposed for $36 \mathrm{hr}$, and developed. The probe specificity was confirmed by competition with a 100 -fold excess of the unlabeled probe.

Radioimmunoassay. To investigate whether lithium treatment may cause a release of oxytocin from oxytocinergic axonal terminals, we examined blood oxytocin levels. Under anesthetization, rats received implantation of cannulas into their jugular veins. The cannulas were then exteriorized through the skin at the back of the neck and flushed daily with diluted heparin. After surgery, rats were handled every day to reduce nonspecific stress responses during the experiment. Blood samples were collected 10,30 , and $50 \mathrm{~min}(0.5 \mathrm{ml}$ each time) after the six animal treatment procedures described under the above "In situ hybridization" section. After centrif ugation, aliquots of plasma were measured for oxytocin concentrations with standard radioimmunoassay procedures according to manufacturer's instructions (Peninsula Laboratories). The sensitivity of the assay was $0.4 \mathrm{pg} / \mathrm{ml}$. The within- and between-assay coefficients of variation for oxytocin detection were 10 and $10 \%$.

Data analysis. The cannabinoid withdrawal syndrome consists of counted signs and observed signs (Table 2) and was measured for $50 \mathrm{~min}$ after AM281 precipitation (De Fonseca et al., 1997; Ledent et al., 1999). Quantification of the cannabinoid withdrawal syndrome was done by summing up counted signs (total number of events during $50 \mathrm{~min}$ ) and observed signs (occurrence of events during $50 \mathrm{~min}$ ).

Sections stained with Fos antibody alone were examined with a Zeiss microscope with bright-field illumination. The relative densities of Fosimmunoreactive cells in various brain regions among different groups of rats receiving different treatments were first compared qualitatively, followed by cell counting of Fos-positive cells in the following hypothalamic regions that showed obvious differences between rats treated with and without lithium: the rostral, ventrolateral, and caudal parts of the paraventricular nucleus and the dorsal part of the supraoptic nucleus. 

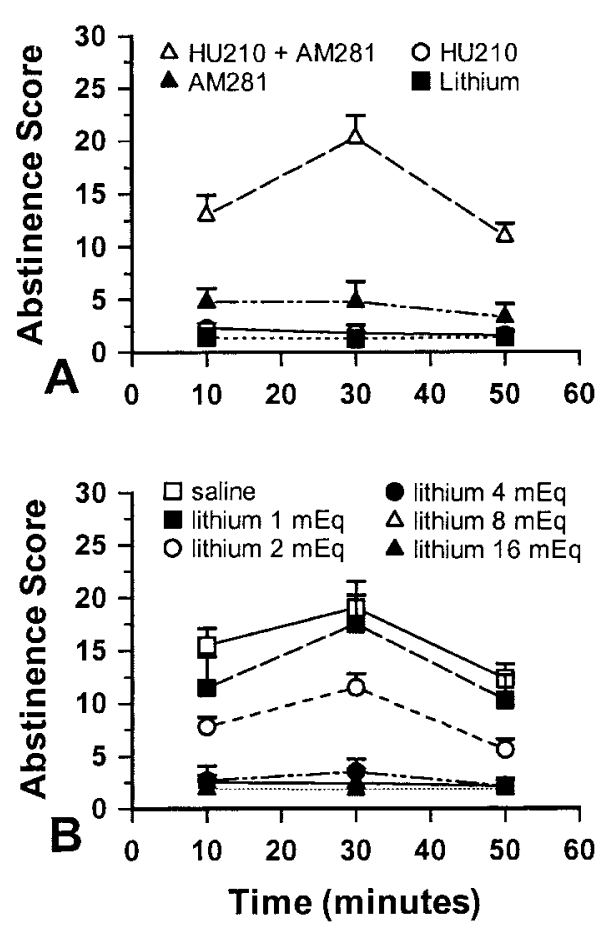

Figure 1. Summed cannabinoid withdrawal scores following different treatments. $A$, AM281 alone induced a mild behavioral change $(\boldsymbol{\Delta})$ and severe abstinence symptoms after daily HU210 injection $(\Delta)$. Daily HU210 (O) or an acute lithium injection alone (ם) did not produce abstinence symptoms. $B$, In comparison with saline $(\square)$ and $1 \mathrm{meq} / \mathrm{kg}$ lithium injection $(\square)$ before AM281 precipitation, $2 \mathrm{meq} / \mathrm{kg}(\bigcirc)$ inhibited $(p<0.05)$ and $4(\bullet), 8(\Delta)$, and $16(\boldsymbol{\Delta}) \mathrm{meq} / \mathrm{kg}$ blocked $(p<0.0001)$ the withdrawal syndrome. Data are mean $\pm \operatorname{SEM}(n=4$ per group).

Cell counting included both sides of these regions from two sections (120 $\mu \mathrm{m}$ apart) collected from groups 5, 8, 11, and 12 (Table 1). Parcellation of each brain region and the associated nomenclature used in the present study were derived mainly from an atlas of the rat brain (Paxinos and Watson, 1998).

One series of sections from groups 5, 8, and 11 (Table 1) were doubly stained with Fos and oxytocin antibodies and then examined with a Nikon confocal microscope equipped with a $60 \times$ objective. A series of adjacent optical sections $(\sim 0.3 \mu \mathrm{m}$ internals $)$ along the $z$-axis were collected for the following selected hypothalamic fields: the rostral, ventrolateral, and caudal parts of the paraventricular nucleus and the dorsal part of the supraoptic nucleus. We paid special attention to these subnuclear regions because they are the hypothalamic areas that contain the biggest number of oxytocinergic neurons in rats (Sofroniew, 1985). Images of immunoreactive cells were color encoded, and maximum image intensity projections, derived from 133 image planes, were prepared. The projected images were evaluated for the presence of Fospositive cell nuclei occurring within the oxytocin-positive neurons. From these projected images, the numbers of oxytocin single-immunolabeled and Fos/oxytocin double-immunostained cells in the hypothalamic paraventricular and supraoptic nucleus were counted. Then, the percentage of the number of Fos/oxytocin doubly labeled neurons to the total number of oxytocin singly labeled cells was calculated.

The $\mathrm{x}$-ray images obtained from in situ hybridization experiments were analyzed semiquantitatively by computerized densitometry using a microcomputer imaging device imaging analyzer (Imaging Research Inc., St. Catharines, Ontario, Canada).

Statistical comparisons of the data obtained were performed using one-way ANOVA for repeated measurements, or one-way ANOVA, succeeded by Scheffe post hoc tests.

\section{RESULTS}

\section{Effects of lithium on cannabinoid withdrawal}

As shown in Figure $1 A$, an acute injection of the cannabinoid antagonist AM281 induced a clear withdrawal syndrome (Table
Table 3. Plasma lithium levels after saline and increasing doses of daily lithium administration $(n=5)$

\begin{tabular}{ll} 
Treatment & $\begin{array}{l}\text { Plasma lithium levels } \\
\text { (meq/l) }\end{array}$ \\
\hline Saline & 0 \\
$1 \mathrm{meq} / \mathrm{kg}$ lithium & $0.17 \pm 0.02$ \\
$2 \mathrm{meq} / \mathrm{kg}$ lithium & $0.43 \pm 0.04$ \\
$4 \mathrm{meq} / \mathrm{kg}$ lithium & $1.24 \pm 0.08$ \\
$8 \mathrm{meq} / \mathrm{kg}$ lithium & $3.12 \pm 0.11$ \\
$16 \mathrm{meq} / \mathrm{kg}$ lithium & $7.81 \pm 0.64$ \\
\hline
\end{tabular}

2) in rats pretreated twice daily with the cannabinoid agonist HU210 (group 1) and a mild behavioral change in drug-free rats receiving AM281 injection after twice daily pretreatment with vehicle (group 2) $\left(F_{(3,12)}=72.787 ; p<0.0001\right)$. The abstinence symptoms became evident in $\sim 10$ min after AM281 injection, peaked at $\sim 30 \mathrm{~min}$, abated thereafter, and disappeared within 60 min after AM281 precipitation. Lithium injection at the $8 \mathrm{meq} / \mathrm{kg}$ dosage to rats receiving five daily pretreatments with vehicle (group 3) did not induce withdrawal symptoms or any other abnormal behavioral changes, such as impaired locomotor activity, etc. Rats pretreated with twice daily HU210 that received vehicle on the test day (group 4) did not exhibit withdrawal signs. These results are in general agreement with those of De Fonseca et al. (1997) and of Ledent et al. (1999).

Saline (group 5) and $1 \mathrm{meq} / \mathrm{kg}$ of lithium chloride injection (group 6) $15 \mathrm{~min}$ before AM281 precipitation in rats received twice daily HU210 injections did not exert significant effects on the cannabinoid withdrawal syndrome (Fig. 1B). Although four other increasing doses of lithium (groups 7-10) produced significant effects on the withdrawal symptoms $\left(F_{(5,18)}=48.583 ; p<\right.$ $0.0001)$, Scheffe post hoc tests revealed that $2 \mathrm{meq} / \mathrm{kg}$ inhibited $(p<0.05)$ and 4,8 , and $16 \mathrm{meq} / \mathrm{kg}$ completely blocked ( $p<$ 0.0001 ) the abstinence syndrome (Fig. 1B). Similar therapeutic effects were also observed with $4 \mathrm{meq} / \mathrm{kg}$ of lithium administered 5 min before AM281 precipitation (group 13). The therapeutic effects of lithium treatment at 4 and above doses persisted over the 50 min of behavioral observation period. Similar to groups 3 and 4, either lithium (group 11) or saline injection (group 12) 15 min before a vehicle injection to rats that had received twice daily vehicle administrations for $5.5 \mathrm{~d}$ did not produce cannabinoid withdrawal syndrome or any other abnormal behavioral changes (results not shown).

\section{Plasma concentrations of lithium}

The plasma lithium levels measured $12 \mathrm{hr}$ after the last dose of twice daily injections of lithium chloride or saline were dose dependent (Table 3). One-way ANOVA analysis revealed a significant difference between groups $\left(F_{(5,24)}=992.763 ; p<0.0001\right)$.

\section{Effects of lithium on oxytocinergic neurons}

In general agreement with recent studies (Yamamoto et al., 1992; Lamprecht and Dudai, 1995; Portillo et al., 1998; Hamamura et al., 2000), a single injection of lithium chloride elicited Fos expression in many brain regions. Thus, although $1 \mathrm{meq} / \mathrm{kg}$ produced no specific Fos immunoreactivity (Fig. $2 A, B$ ), 2 meq $/ \mathrm{kg}$ induced Fos expression in the hypothalamic paraventricular and supraoptic nuclei and central amygdaloid nucleus. The $4 \mathrm{meq} / \mathrm{kg}$ dose further induced Fos expression in both these regions (Fig. $2 C, D)$ and other hypothalamic areas, nucleus accumbens, bed nuclei of the stria terminalis, midline thalamic nuclei, substantia 
Li (1 mEq/kg)

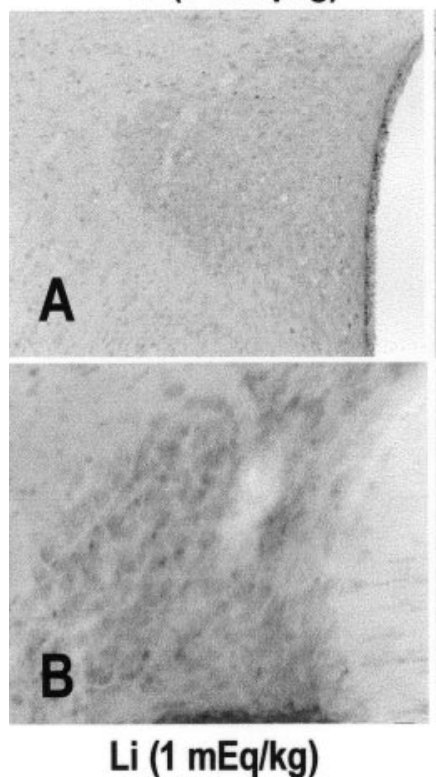

Li (4 mEq/kg)

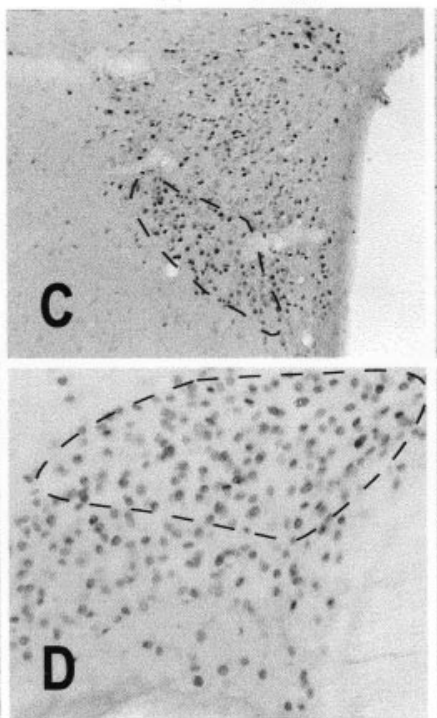

Li (4 mEq/kg)
HU210 + AM281

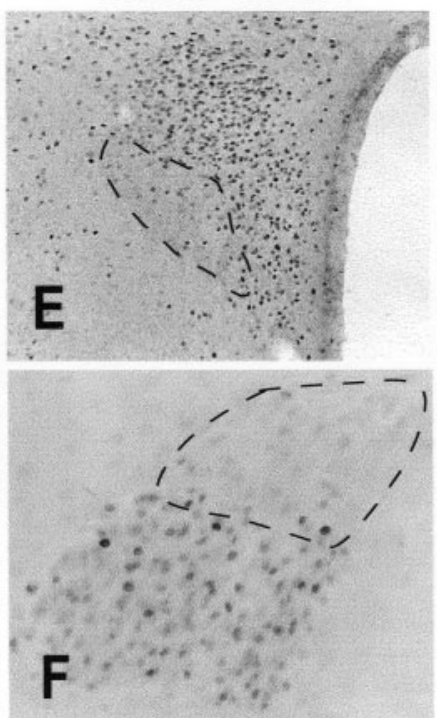

HU210 + AM281
Saline

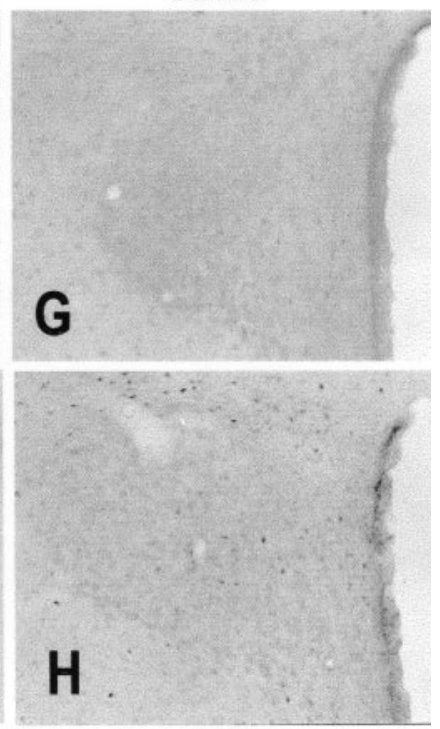

AM281

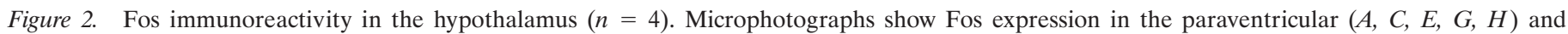

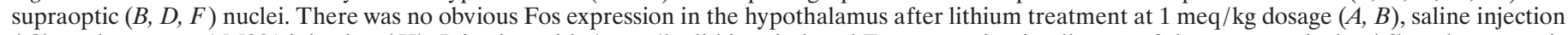

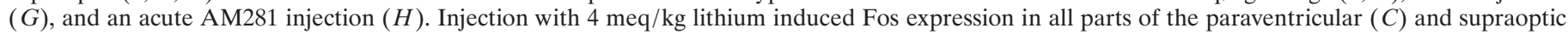

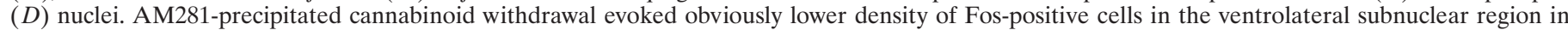

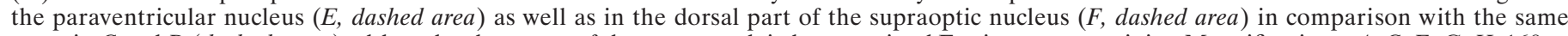

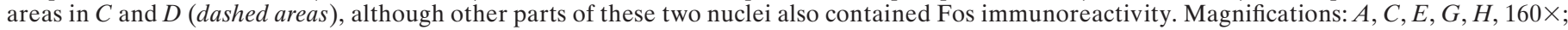
$B, D, F, 320 \times$.

Table 4. Average numbers of Fos-immunoreactive cells in the hypothalamic paraventricular (PVN) and supraoptic nuclei (SON) after different treatments (see groups $5,8,11$, and 12 in Table 1) $(n=4)$

\begin{tabular}{|c|c|c|c|c|}
\hline & Rostral PVN & $\begin{array}{l}\text { Ventrolateral } \\
\text { PVN }\end{array}$ & Caudal PVN & Dorsal SON \\
\hline HU210 + lithium + AM281 & $36.5 \pm 1.9^{* *}$ & $74.9 \pm 4.3^{* *}$ & $37.7 \pm 1.7^{* *}$ & $112 \pm 4.7^{* *}$ \\
\hline HU210 + vehicle + AM281 & $9.1 \pm 1.1^{*}$ & $17.8 \pm 1.4^{*}$ & $8.8 \pm 0.9^{*}$ & $37.4 \pm 1.8^{*}$ \\
\hline Vehicle + lithium + vehicle & $41.8 \pm 2.2^{* *}$ & $82.1 \pm 5.5^{* *}$ & $39.8 \pm 1.2^{* *}$ & $107 \pm 4.1^{* *}$ \\
\hline Vehicle + vehicle + vehicle & $0.8 \pm 0.14^{*}$ & $2.1 \pm 0.12^{*}$ & $0.4 \pm 0.07 *$ & $1.3 \pm 0.08^{*}$ \\
\hline
\end{tabular}

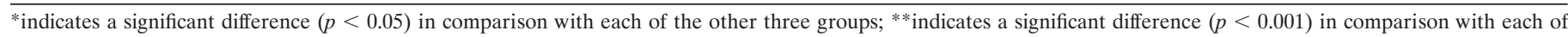
the other two groups labeled with *.

nigra, ventral tegmental area, parabrachial nucleus, central gray, locus coeruleus, nucleus of the solitary tract, and area postrema. A similar pattern of Fos expression was also seen in rats receiving 8 and $16 \mathrm{meq} / \mathrm{kg}$ of lithium.

The widespread distribution pattern of Fos immunoreactivity in the brain produced by $4-16 \mathrm{meq} / \mathrm{kg}$ of lithium treatment alone was indistinguishable from that induced by AM281-precipitated cannabinoid withdrawal with or without lithium treatment (4-16 $\mathrm{meq} / \mathrm{kg}$ ). After a careful comparison of the subnuclear distribution patterns, however, we found the following results: although lithium-treated rats displayed Fos expression in all parts of both the paraventricular and supraoptic nuclei (Fig. 2C,D), those treated with AM281 precipitation without lithium showed significantly lower densities of Fos-immunoreactive cells in the rostral, ventrolateral, and caudal parts of the paraventricular nucleus (Fig. 2E) and the dorsal part of the supraoptic nucleus (Fig. 2F). Fos induction in the paraventricular and supraoptic nuclei after cannabinoid withdrawal was specifically associated with the withdrawal response, because neither twice daily HU210 injection alone nor an acute injection of AM281 or saline alone produced obvious Fos expression in these nuclei (Fig. 2G,H). Cell counting revealed that the number of Fos-positive cells in the rostral, ventrolateral, and caudal parts of the paraventricular nucleus and the dorsal part of the supraoptic nucleus was significantly greater $(p<0.05)$ in the rats receiving lithium treatment with or without cannabinoid withdrawal reaction (groups 8 and 11 in Table 1) than in those rats showing the cannabinoid withdrawal syndrome without lithium treatment (group 5 in Table 1) or vehicle injection (group 12 in Table 1) (Table 4).

Given that these subnuclear regions of the paraventricular and supraoptic nuclei with significantly less Fos expression without lithium treatment (Fig. 2E,F) are the major source of oxytocin in the brain (Sofroniew, 1985), it is not surprising to find, with confocal microscopy, that the majority of Fos-immunoreactive neurons in these regions in rats receiving lithium were also doubly stained with oxytocin immunoreactivity (Fig. $3 A, B$ ). In addition, many double-labeled cells were present in other paraventricular and supraoptic subnuclear regions, as well as in the hypothalamic oxytocin accessory nuclei including the nucleus circularis (Fig. $3 C)$. The percentage of the number of Fos/oxytocin double- 
Figure 3. Microphotographs showing doubleimmunofluorescent labeling revealed by a confocal microscopy. Fos (green) and oxytocin (red) immunostaining was located in the same individual neurons (yellow) in the ventromedial $(A)$ and posterior parts $(B)$ of the paraventricular nucleus. $C$, Double labeling was also present in neurons in the nucleus circularis located between the paraventricular and supraoptic nuclei. $V$ in $A$ indicates the third ventricle, and dashed area in $C$ indicates
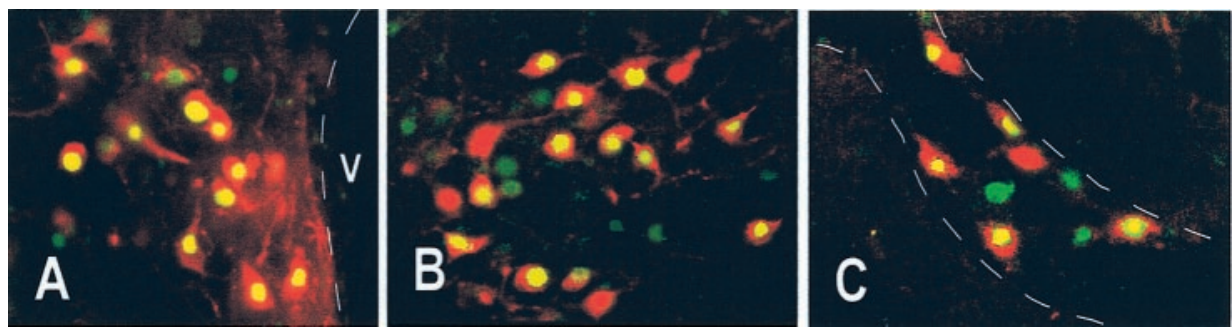
a blood vessel. Magnification: $400 \times$.

Table 5. Percentage of the number of Fos/oxytocin double-labeled neurons to the total number of oxytocin single-labeled cells in the hypothalamus

\begin{tabular}{lll} 
& $\begin{array}{l}\text { Fos/oxytocin cells } \\
\text { in PVN }(\%)\end{array}$ & $\begin{array}{l}\text { Fos/oxytocin cells } \\
\text { in SON }(\%)\end{array}$ \\
\hline HU210 + lithium + AM281 & $87.0 \pm 6.2$ & $92.3 \pm 5.2$ \\
HU210 + vehicle + AM281 & $37.0 \pm 4.3^{*}$ & $38.3 \pm 3.6^{*}$ \\
Vehicle + lithium + vehicle & $90.0 \pm 4.9$ & $88.0 \pm 5.7$
\end{tabular}

The numbers of oxytocin single-labeled cells and Fos/oxytocin double-stained cells in the paraventricular (PVN) and supraoptic nuclei (SON) were counted from the projected images obtained from a confocal microscopy (see Materials and Methods). Three groups of rats receiving different treatments (see groups 5, 8, and 11 in Table $1)$ were compared $(n=4)$.

*indicates a significant difference $(p<0.001)$ in comparison with each of the other two groups.

labeled neurons to the total number of oxytocin single-labeled cells in the paraventricular and supraoptic nuclei was depicted in Table 5. One-way ANOVA revealed that rats receiving lithium pretreatment showed significantly more Fos/oxytocin doubly labeled cells in both the paraventricular and supraoptic nuclei than those rats without lithium pretreatment $\left[F_{(2,9)}=32.493\right.$ (the paraventricular nucleus), $F_{(2,9)}=37.848$ (the supraoptic nucleus); $p<0.0001]$. Lithium treatment with or without AM281 precipitation produced similar results, and the same group of rats showed similar percentage of Fos/oxytocin doubly labeled cells between the paraventricular and supraoptic nuclei (Table 5).

Colocalization of Fos and oxytocin immunoreactivity in the same hypothalamic neurons after lithium treatment led us to perform an in situ hybridization experiment to explore whether lithium could induce oxytocin mRNA expression in the hypothalamus. We observed the following results (Fig. 4): in comparison with oxytocin mRNA expression in the paraventricular and supraoptic nuclei in rats that experienced saline injection, daily HU210 injection or an acute AM281 injection, oxytocin mRNA expression levels were significantly higher in those rats that experienced lithium treatment alone and AM281-precipitated cannabinoid withdrawal with or without lithium treatment $(p<$ $0.0001)$. One-way ANOVA analysis revealed a significant difference between groups $\left(F_{(5,18)}=322.930, p<0.0001\right.$ for the paraventricular nucleus; $F_{(5,18)}=300.648, p<0.0001$ for the supraoptic nucleus).

Furthermore, we also performed a radioimmunoassay test to examine whether lithium treatment could elevate the plasma oxytocin levels. In comparison with rats receiving saline injection, rats that experienced an acute lithium injection alone and AM281-precipitated cannabinoid withdrawal with or without lithium treatment $(4 \mathrm{meq} / \mathrm{kg})$ displayed a rapid and significant $(p<$ $0.05-0.0001)$ increase in the plasma oxytocin levels within $10 \mathrm{~min}$ after lithium or AM281 injection (a 21-, 30-, and 12-fold increase, respectively, for rats that experienced lithium treatment alone and AM281-precipitated cannabinoid withdrawal with or without lithium treatment) (Fig. 5). Then, the plasma oxytocin concentrations decreased continuously and dramatically toward the basal levels over the next $40 \mathrm{~min}$. One-way ANOVA for repeated measurements revealed a significant group effect $\left(F_{(5,18)}=\right.$ 39.829; $p<0.0001)$ and a significant interaction of the groups over time $\left(F_{(10,18)}=8.190 ; p<0.0001\right)$. The present observation of lithium-induced significant increase in the plasma oxytocin levels is in agreement with previous studies measuring plasma levels of oxytocin-associated neurophysin after lithium injection (O’Connor et al., 1987).

\section{Effects of oxytocin antagonist on the action of lithium}

The above results led us to examine the possible involvement of oxytocinergic neuronal activation in the action of lithium against the cannabinoid withdrawal syndrome. We observed that a systemic injection of the oxytocin receptor antagonist L-368,899 before lithium treatment (group 14) blocked the effects of lithium against AM281-precipitated cannabinoid withdrawal syndrome (group 15) (Fig. 6). L-368,899 injection without subsequent lithium treatment (group 16) significantly enhanced AM281precipitated cannabinoid withdrawal syndrome over that seen in rats without L-368,899 (group 17) (Fig. 6). In another group of rats, we found that L-368,899 injection alone did not induce withdrawal-like behavior in drug-free rats (group 18) (Fig. 6), suggesting that the enhancement of AM281-precipitated cannabinoid withdrawal syndrome by L-368,899 is not caused by L-368,899 itself. One-way ANOVA revealed a significant group effect $\left(F_{(4,15)}=52.509 ; p<0.001\right)$ and a significant interaction of the groups over time $\left(F_{(8,15)}=4.586 ; p<0.0001\right)$.

\section{Effects of oxytocin on cannabinoid withdrawal}

We also observed that similar to lithium treatment, a systemic (200 $\mu \mathrm{g} / \mathrm{kg})$ and intracerebroventricular injection $(2 \mu \mathrm{g} / \mathrm{kg})$ of oxytocin (groups 19 and 22) and a systemic injection of oxytocin fragment 4-9 (2 $\mu \mathrm{g} / \mathrm{kg})$ (group 20) prevented cannabinoid withdrawal syndrome in comparison with a systemic and intracerebroventricular injection of saline (groups 21 and 23) (Fig. 7). One-way ANOVA analysis revealed a significant group effect $\left(F_{(4,15)}=97.376 ; p<0.001\right)$ and a significant interaction of the groups over time $\left(F_{(8,15)}=17.471 ; p<0.0001\right)$.

\section{DISCUSSION}

The present study provides the first evidence that lithium and oxytocin are capable of preventing the cannabinoid withdrawal syndrome in rats. This study also shows, for the first time, that the effects of lithium against the cannabinoid withdrawal syndrome are likely mediated by activation of the oxytocinergic neuronal system in the CNS.

\section{Mediation of the action of lithium by oxytocin}

We found that lithium treatment produced expression of Fos proteins within most oxytocin-immunoreactive neurons in the 


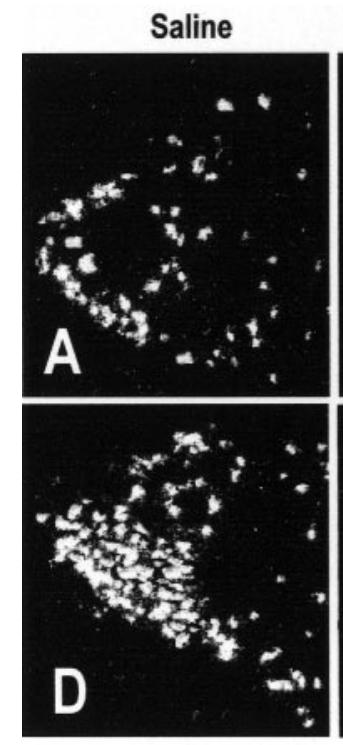

$H U+A M$

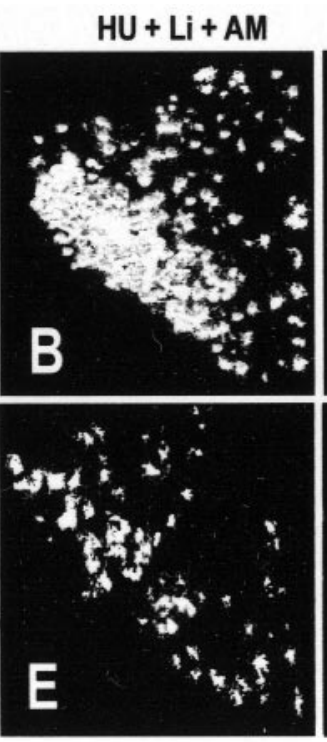

HU

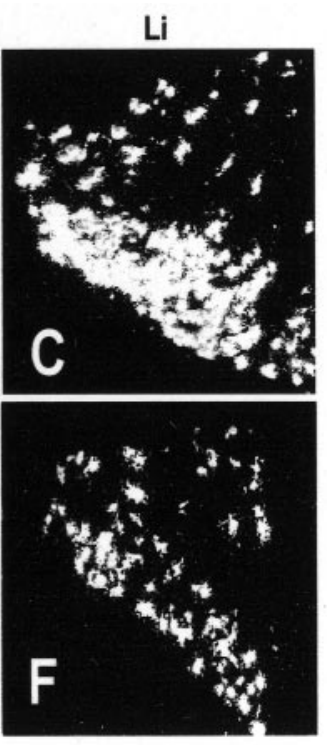

AM

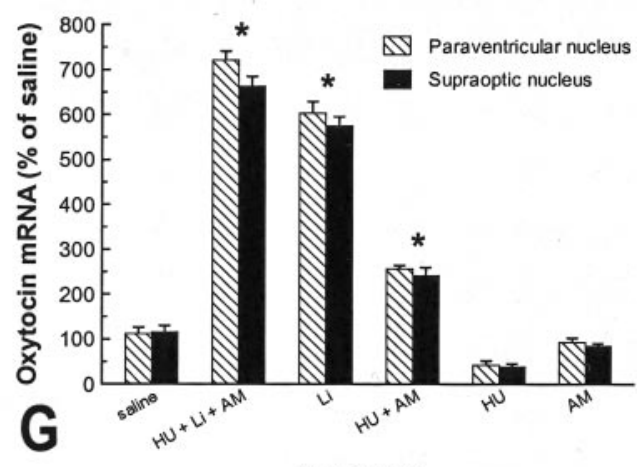

Treatment

Figure 4. Hypothalamic oxytocin mRNA expression after different treatments ( $n=4$ per group). $A-F$, Microphotographs showing the relative density and distribution of oxytocin mRNA expression in the paraventricular nucleus after saline injection (saline), lithium treatment before AM281-precipitated cannabinoid withdrawal $(H U+L i+A M)$, lithium alone $(L i)$, AM281-precipitated cannabinoid withdrawal $(H U+A M)$, twice daily HU210 $(H U)$, and a single AM281 injection $(A M)$. Magnification: $280 \times$. $G$, Densitometry of oxytocin mRNA in the hypothalamic paraventricular $(P V N)$ and supraoptic nuclei $(S O N)$. * Indicates a significant difference in comparison with each of the three groups labeled with * $(p<0.001)$ as well as with each of the other three groups without the label * $(p<0.001)$.

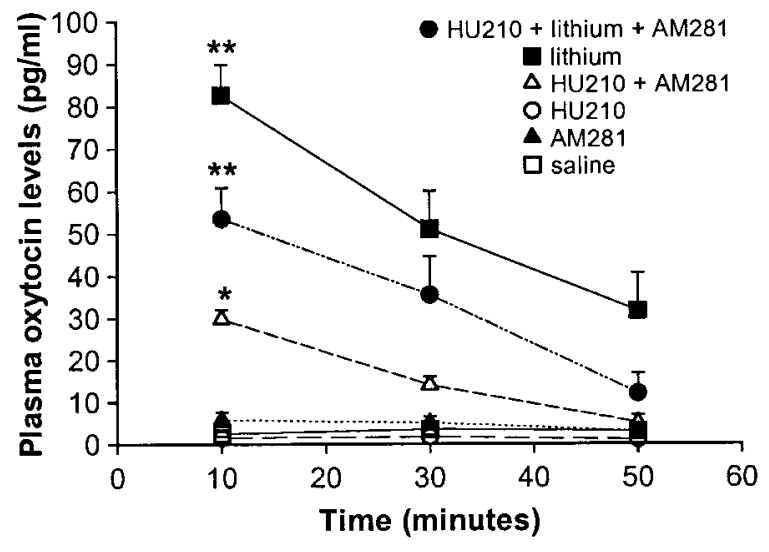

Figure 5. Oxytocin concentrations in the plasma after different treatments $(n=4$ per group). AM281-precipitated cannabinoid withdrawal with $(\square)$ or without $(\Delta)$ lithium treatment $(4 \mathrm{meq} / \mathrm{kg})$ and an acute lithium injection alone (-) rapidly and significantly elevated the plasma oxytocin levels, in comparison with saline injection ( $\square$ ), twice daily injection of HU210 (O), and an acute AM281 injection (A), which produced similarly low plasma levels of oxytocin $(p>0.05) .{ }^{*}$ indicates $p<0.05 ;{ }^{* *} p<0.0001$ in comparison with saline injection.

hypothalamic paraventricular and supraoptic nuclei. Because it is now widely accepted that the expression of Fos protein in the brain can be used as an endogenous marker of neuronal activation (for review, see Morgan and Curran, 1995; Chaudhuri, 1997), our finding suggests that the majority of paraventricular and supraoptic oxytocinergic neurons may be activated by lithium. This suggestion is further supported by our observations that lithium treatment alone or combined with cannabinoid withdrawal produced a significant increase in oxytocin mRNA expression in the hypothalamic paraventricular and supraoptic nuclei, although it is unknown whether oxytocin mRNA expression might result from

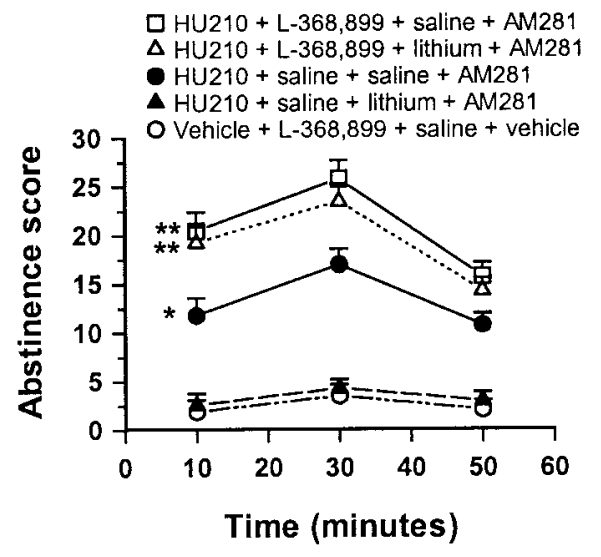

Figure 6. Effects of oxytocin antagonist L-368,899 on the action of lithium against the cannabinoid withdrawal syndrome. Five groups of six rats each were given different treatments (see Table 1 and Materials and Methods). *Indicates a significant difference $(p<0.05)$ in comparison with each of the other four groups; $* *$ indicates a significant difference $(p<0.001)$ in comparison with $\boldsymbol{\Delta}(\mathrm{HU} 210+$ saline + lithium + AM210) or 79 (vehicle + L-368,899+ saline + vehicle).

(or induced by) c-fos gene expression, as occurred elsewhere in other experimental models (for review, see Morgan and Curran, 1991, 1995).

The exact mechanism or mechanisms of oxytocinergic neuronal activation by lithium is not clear. It is possible that oxytocinergic neuronal activation (or Fos expression in oxytocinergic neurons) after lithium treatment may be achieved by the feedback stimulation of oxytocinergic neurons after a prominently elevated release of oxytocin from the posterior pituitary into the peripheral blood. This hypothesis is supported by our findings that there was an $\sim 20$ - to 30 -fold increase in the oxytocin levels in the plasma within 10 min after lithium administration. This immedi- 


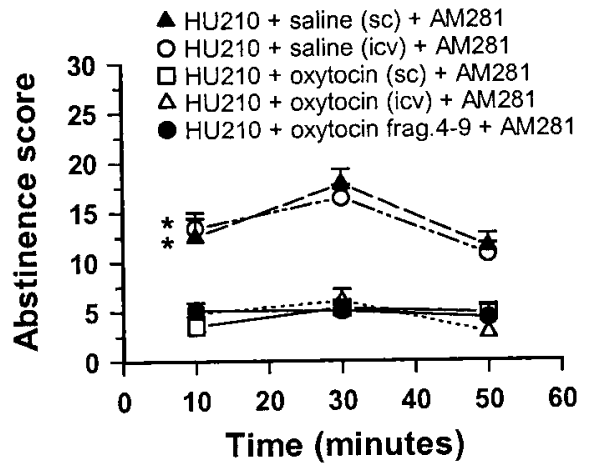

Figure 7. Effects of oxytocin on the cannabinoid withdrawal syndrome after different treatments ( $n=6$ per group) (see Table 1 and Materials and Methods for treatment protocols). *Indicates a significant difference $(p<0.001)$ in comparison with each of the other three groups without the label *.

ate and large quantity release of oxytocin by lithium may also be used to explain the rapid expression of oxytocin mRNA $1 \mathrm{hr}$ after lithium administration. On the other hand, it is also possible that oxytocinergic neuronal activation after lithium treatment may result from direct stimulation of lithium on oxytocinergic neurons, although at the present time we do not have available evidence in support of this hypothesis.

Ample evidence has shown that activation of hypothalamic oxytocinergic neurons can lead to release and subsequent action of oxytocin on oxytocin receptors located in both the CNS and PNS (Patchev et al., 1993; Yoshimura et al., 1993; Condes-Lara et al., 1994; Ludwig, 1995; McCarthy and Altemus, 1997; UvnasMoberg, 1997; Hatton and Li, 1998; Raggenbass et al., 1998; Vaccari et al., 1998). That is, although activation of the hypothalamic oxytocinergic neurons can release oxytocin into the peripheral blood to act on the peripheral system, the activated hypothalamic neurons can also release oxytocin from oxytocinergic axonal terminals to act on oxytocin receptors in widespread brain regions. We therefore hypothesize that the effects of lithium against the cannabinoid withdrawal syndrome are mediated by the oxytocinergic neuronal activation and subsequent release and action of oxytocin within the CNS. This hypothesis is supported by our following findings. First, injection of the oxytocin receptor antagonist L-368,899 before lithium treatment blocked the effects of lithium against AM281-precipitated cannabinoid withdrawal. Second, L-368,899 injection without subsequent lithium treatment significantly enhanced AM281-precipitated cannabinoid withdrawal over that seen in rats without L-368,899. Third, L-368,899 did not induce withdrawal-like behavior in drug-free rats. Finally, oxytocin administration mimicked the effects of lithium against the cannabinoid withdrawal syndrome.

Although AM281-precipitated cannabinoid withdrawal also activated oxytocinergic neurons, the degree of oxytocinergic activation is much weaker than that induced by lithium. Because central administration of oxytocin prevented the cannabinoid withdrawal syndrome, and because blockade of oxytocin receptors by L-368,899 significantly enhanced the withdrawal syndrome, the notion is tenable that the relatively mild activation of oxytocinergic neurons by AM281-precipitated cannabinoid withdrawal functions to ameliorate abstinence symptoms, as suggested elsewhere in studies of stress (McCarthy and Altemus, 1997).

Our finding that oxytocin blocked the cannabinoid withdrawal syndrome is consistent with other results indicating anti-stress and anxiolytic effects of oxytocin in both animals and humans. For example, central administration of oxytocin to both male and female rats has been observed to exert an anxiolytic effect (McCarthy and Altemus, 1997; Windle et al., 1997; Neumann et al., 2000) that could be blocked by oxytocin receptor antagonists (Uvnas-Moberg, 1997). Oxytocin exerts antidepressant effects in the rat depression models of learned helplessness and behavioral despair (McCarthy and Altemus, 1997). Lactating rats with high levels of oxytocin in the blood are less responsive to certain stressful stimuli than nonlactating female rats (Uvnas-Moberg, 1997). Breastfeeding women with high levels of oxytocin in the blood are calmer and more social than age-matched women who are not breastfeeding or pregnant (Uvnas-Moberg, 1997). Women with panic disorder can experience relief of symptoms during lactation, and frequently relapse after weaning (Klein et al., 1995), an effect that is also seen with depression (Susman and Katz, 1988).

\section{Beneficial effects of lithium and oxytocin}

The beneficial effects of lithium against the cannabinoid withdrawal syndrome in rats appear not to be related to its mood stabilizing action, because injection of another mood stabilizer and anti-epileptic drug, sodium valproate (Gelder et al., 1999), to rats that had received twice daily injections of HU210 for $5.5 \mathrm{~d}$ produced no obvious inhibitory effects on AM281-precipitated cannabinoid withdrawal, but stimulated seizure-like behavioral changes, such as frequent wet-dog shakes and forelimb clonus, etc. (X. Zhang, Y. Li, and S. S. Cui, unpublished observation). A possible explanation for the lack of improvement by valproate on the cannabinoid withdrawal syndrome is the observation that valproate does not induce oxytocin release (Chiodera et al., 1993). Furthermore, we have shown here that the action of lithium against the cannabinoid withdrawal syndrome takes place within minutes of drug administration, unlike the therapeutic effects of lithium on bipolar mood disorder, which takes several days to develop. The rapid onset of these effects is of possible clinical importance because cannabis abstinence symptoms in patients usually heighten within the first week after abrupt cessation (Jones et al., 1976; Mendelson et al., 1984; Haney et al., 1999b).

Although toxic symptoms induced by lithium in humans have never been reported in rats, we measured the plasma lithium levels in rats after different doses of lithium treatment to provide complimentary data for possible clinical use. We found that the cannabinoid withdrawal syndrome was substantially inhibited by a $2 \mathrm{meq} / \mathrm{kg}$ dosage of lithium, which produced steady-state plasma levels of $0.43 \pm 0.04 \mathrm{meq} / \mathrm{l}$. The withdrawal syndrome was completely blocked by a $4 \mathrm{meq} / \mathrm{kg}$ dosage of lithium, which produced $1.24 \pm 0.08 \mathrm{meq} / 1$ steady-state plasma levels. This is close to the clinically effective therapeutic range of lithium $(0.8-1.2 \mathrm{meq} / \mathrm{l})$ (Gelder et al., 1999).

In the present study we also observed that similar to lithium treatment, a systemic injection of a high dose of oxytocin (200 $\mu \mathrm{g} / \mathrm{kg}$ ) also blocked the cannabinoid withdrawal syndrome. The beneficial effects of peripherally applied oxytocin against the cannabinoid withdrawal syndrome are very likely achieved through brain oxytocin receptors, because we have shown here that an intracerebroventricular application of oxytocin at a concentration 100 times lower than the systemic injection mimicked the effects achieved by the systemic injection. The idea that systemically applied oxytocin at $0.2-1 \mathrm{mg} / \mathrm{kg}$ doses does cross the blood-brain barrier (BBB) in amounts obviously sufficient to 
induce central actions has also been supported by several studies. Thus, Mens et al. (1983) observed that $\sim 0.02 \%$ of the peripherally applied amount of oxytocin reached the CNS at 10 min after injection. Uvnas-Moberg (1997) demonstrated that a single systemic injection of oxytocin in rats resulted in rapid anxiolytic and sedative effects. More interestingly, an intracerebroventricular injection of an oxytocin receptor antagonist (50 pg) completely abolished the suppression effects of peripherally applied oxytocin $(0.5 \mu \mathrm{g})$ on cocaine-induced sniffing behavior in mice (Sarnyai, 1998).

Nevertheless, the BBB is obviously a major obstacle for the access of peripherally applied oxytocin into the brain. Based on the observation that oxytocin fragment 4-9 could exert effects in the brain $\sim 100$ times more potent than the oxytocin whole peptide (Burbach et al., 1983), we have tested the effects of oxytocin fragment 4-9 on the cannabinoid withdrawal syndrome. We observed that a systemic injection of $2 \mu \mathrm{g} / \mathrm{kg}$ of oxytocin fragment 4-9 mimicked the therapeutic effects of $200 \mu \mathrm{g} / \mathrm{kg}$ of the oxytocin whole peptide in antagonizing the cannabinoid withdrawal symptoms. These results warrant further exploration of potent oxytocin agonists that can cross the BBB, so that a small amount of such agonists can antagonize cannabinoid withdrawal without producing unwanted peripheral side effects.

In summary, the present study has demonstrated novel findings that systemic injection of lithium or oxytocin produces rapid and potent suppressing effects against the cannabinoid withdrawal syndrome in rats, and thus warrants further assessment of the effects of lithium or oxytocin for treating cannabis withdrawal and dependence in humans, given that the degree of physical dependence to an illicit drug is characterized by the severity of withdrawal reactions.

\section{REFERENCES}

American Psychiatry Association (1994) Diagnostic and statistical manual of mental disorders. Washington, DC: American Psychiatric Association.

Budney AJ, Kandel DB, Cherek DR, Martin BR, Stephens RS, Roffman R (1997) College on problems of drug dependence meeting, marijuana use and dependence. Puerto Rico (June 1996). Drug Alcohol Depend 45:1-11.

Budney AJ, Radonovich KJ, Higgins ST, Wong CJ (1998) Adults seeking treatment for marijuana dependence: a comparison with cocainedependent treatment seekers. Exp Clin Psychopharmacol 6:419-426.

Budney AJ, Novy PL, Hughes JR (1999) Marijuana withdrawal among adults seeking treatment for marijuana dependence. Addiction 94:1311-1322.

Burbach JP, Bohus B, Kovacs GL, Van Nispen JW, Greven HM, De Wied D (1983) Oxytocin is a precursor of potent behaviorally active neuropeptides. Eur J Pharmacol 94:125-131.

Chaudhuri A (1997) Neural activity mapping with inducible transcription factors. NeuroReport 8:13-17.

Chiodera P, Volpi R, Capretti L, Bocchi R, Caffarri G, Marcato A, Rossi G, Coiro V (1993) Gamma-aminobutyric acid mediation of the inhibitory effect of endogenous opioids on the arginine vasopressin and oxytocin responses to nicotine from cigarette smoking. Metabolism 42:762-765.

Condes-Lara M, Veinante P, Rabai M, Freund-Mercier MJ (1994) Correlation between oxytocin neuronal sensitivity and oxytocin-binding sites in the amygdala of the rat: electrophysiological and histoautoradiographic study. Brain Res 637:277-286.

Cottler LB, Schuckit MA, Helzer JE, Crowley T, Woody G, Nathan P, Hughes J (1995) The DSM-IV field trial for substance use disorders: major results. Drug Alcohol Depend 38:59-69.

De Fonseca FR, Carrera MRA, Navarro M, Koob GF, Weiss F (1997) Activation of corticotropin-releasing factor in the limbic system during cannabinoid withdrawal. Science 276:2050-2054.

Donnelly N, Hall W (1994) Patterns of cannabis use in Australia, north drug strategy, monograph 27. Canberra, Australia: Australian Government Publishing Service.

Gerfen CR, Sawchenko PE (1984) An anterograde neuroanatomical tracing method that shows the detailed morphology of neurons, their axons and terminals: immunohistochemical localization of an axonally transported plant lectin, Phaseolus vulgaris leucoagglutinin (PHA-L). Brain Res 290:219-238.

Gelder M, Mayou R, Geddes J (1999) In: Psychiatry, Ed 2 (Gelder M, Mayou R, Geddes J, eds), pp 353-354. New York: Oxford UP.

Grinspoon L, Bakalar JB (1992) Marijuana. In: Substance abuse: a comprehensive textbook, Ed 2 (Lowinson JH, Ruiz P, Millman RS, eds), pp 236-246. Baltimore: Williams \& Wilkins.

Hamamura T, Lee Y, Ohashi K, Fujiwara Y, Miki M, Suzuki H, Kuroda S (2000) A low dose of lithium chloride selectively induces Fos protein in the central nucleus of the amygdala of rat brain. Prog Neuropsychopharmacol Biol Psychiatry 24:285-294.

Haney M, Ward AS, Comer SD, Foltin RW, Fischman MW (1999a) Abstinence symptoms following oral THC administration to humans. Psychopharmacology 141:385-394.

Haney M, Ward AS, Comer SD, Foltin RW, Fischman MW (1999b) Abstinence symptoms following smoked marijuana in humans. Psychopharmacology 141:395-404.

Hatton GI, Li Z-H (1998) Neurophysiology of magnocellular neuroendocrine cells: recent advances. Prog Brain Res 119:77-99.

Ivell R, Richter D (1984) Structure and comparison of the oxytocin and vasopressin genes from the rat. Proc Natl Acad Sci USA 81:2006-2010.

Jefferson JW (1987) Lithium encyclopedia for clinical practice, Ed 2 (Jefferson JW, ed). Washington, DC: American Psychiatric.

Jones RT, Benowitz N, Bachman J (1976) Clinical studies of cannabis tolerance and dependence. Ann NY Acad Sci 282:221-239.

Kandel DB, Chen K, Warner L, Kessler R, Grant B (1997) Prevalence and demographic correlates of symptoms of dependence on cigarettes, alcohol, marijuana and cocaine in the U.S. population. Drug Alcohol Depend 44:11-29.

Klein DF, Skrobala AM, Garfinkel RS (1995) Preliminary look at the effects of pregnancy on the course of panic disorder. Anxiety 1:227-232.

Kouri EM, Pope HG (2000) Abstinence symptoms during withdrawal from chronic marijuana use. Exp Clin Psychopharmacol 8:483-492.

Kovacs G, Sarnyai Z, Szabo G (1998) Oxytocin and addiction: a review. Psychoneuroendocrinology 23:945-962.

Lamprecht R, Dudai Y (1995) Differential modulation of brain immediate early genes by intraperitoneal LiCl. NeuroReport 7:289-293.

Ledent C, Valverde O, Cossu G, Petitet F, Aubert J-F, Beslot F, Bohme GA, Imperato A, Pedrazzini T, Roques BP, Vassart G, Fratta W, Parmentier M (1999) Unresponsiveness to cannabinoids and reduced addictive effects of opiates in CB1 receptor knockout mice. Science 283:401-404.

Ludwig K (1995) Functional role of intrahypothalamic release of oxytocin and vasopressin: consequences and controversies. Am J Physiol 268:E537-E545.

Manji HK, Potter WZ, Lenox RH (1995) Signal transduction pathways. Molecular targets for lithium's actions. Arch Gen Psychiatry 52:531-543

McCarthy MM, Altemus M (1997) Central nervous system actions of oxytocin and modulation of behavior in humans. Mol Med Today 3:269-275.

McLellan AT, Lewis DC, O'Brien CP, Kleber HD (2000) Drug dependence, a chronic medical illness: implications for treatment, insurance, and outcomes evaluation. JAMA 284:1689-1695.

Mendelson JH, Mello NK, Lex BW, Bavli S (1984) Marijuana withdrawal syndrome in a woman. Am J Psychiatry 141:1289-1290.

Mens WB, Witter A, van Wimersma Greidanus TB (1983) Penetration of neurohypophyseal hormones from plasma into cerebrospinal fluid (CSF): half-times of disappearance of these neuropeptides from CSF. Brain Res 262:143-149.

Morgan JI, Curran T (1991) Stimulus-transcription coupling in the nervous system: involvement of the inducible proto-oncogenes fos and jun. Annu Rev Neurosci 14:421-451.

Morgan JI, Curran T (1995) Immediate-early genes: ten years on. Trends Neurosci 18:66-67.

Neumann ID, Torner L, Wigger A (2000) Brain oxytocin: differential inhibition of neuroendocrine stress responses and anxiety-related behaviour in virgin, pregnant and lactating rats. Neuroscience 95:567-575.

O'Connor EF, Cheng SWT, North WG (1987) Effects of intraperitoneal injection of lithium chloride on neurohypophyseal activity: implications for behavioral studies. Physiol Behav 40:91-95.

Patchev VK, Schlosser SF, Hassan AH, Almeida OF (1993) Oxytocin binding sites in rat limbic and hypothalamic structures: site-specific modulation by adrenal and gonadal steroids. Neuroscience 57:537-543.

Paxinos G, Watson C (1998) The rat brain in stereotaxic coordinates, Ed 4. New York: Academic.

Portillo F, Carrasco M, Vallo JJ (1998) Separate populations of neurons within the paraventricular hypothalamic nucleus of the rat project to vagal and thoracic autonomic preganglionic levels and express c-Fos protein induced by lithium chloride. J Chem Neuroanat 14:95-102.

Raggenbass M, Alberi S, Zaninetti M, Pierson P, Dreifuss JJ (1998) Vasopressin and oxytocin action in the brain: cellular neurophysiological studies. Prog Brain Res 119:263-273. 
Sarnyai Z (1998) Oxytocin and neuroadaptation to cocaine. Prog Brain Res 119:449-466.

Sofroniew MV (1985) Vasopressin, oxytocin and their related neurophysins. In: Handbook of chemical neuroanatomy, Vol 4, GABA and neuropeptides in the CNS, Part I (Bjorklund A, Hokfelt T, eds), pp 93-165. Amsterdam: Elsevier.

Stephens RS, Roffman RA, Simpson EE (1993) Adult marijuana users seeking treatment. J Consult Clin Psychol 61:1100-1104.

Stephens RS, Roffman RA, Simpson EE (1994) Treating adult marijuana dependence: a test of the relapse prevention model. J Consult Clin Psychol 62:92-99.

Substance Abuse, Mental Health Services Administration (1996) Preliminary estimates from 1995 National Household Survey on Drug Abuse (Advanced Report No. 18). Rockville, MD: US Department of Health and Human Services.

Susman VL, Katz JL (1988) Weaning and depression: another postpartum complication. Am J Psychiatry 145:498-501.

Tanda G, Pontieri FE, Di Chiara G (1997) Cannabinoid and heroin activation of mesolimbic dopamine transmission by a common $\mu_{1}$ opioid receptor mechanism. Science 276:2048-2050.

Uvnas-Moberg K (1997) Oxytocin linked antistress effects-the relaxation and growth response. Acta Physiol Scand [Suppl] 640:38-42.

Vaccari C, Lolait SJ, Ostrowski NL (1998) Comparative distribution of vasopressin $\mathrm{V} 1 \mathrm{~b}$ and oxytocin receptor messenger ribonucleic acids in brain. Endocrinology 139:5015-5033.

Wiesbeck GA, Schuckit MA, Kalmijn JA, Tipp JE, Bucholz KK, Smith
TL (1996) An evaluation of the history of a marijuana withdrawal syndrome in a large population. Addiction 91:1469-1478.

Windle RJ, Shanks N, Lightman SL, Ingram CD (1997) Central oxytocin administration reduces stress-induced corticosterone release and anxiety behavior in rats. Endocrinology 138:2829-2834.

Wisden W, Morris BJ (1994) In situ hybridization with synthetic oligonucleotide probes. In: In situ hybridization protocols for the brain (Wisden W, Morris BJ, eds), pp 9-34. London: Academic.

Yamamoto T, Shimura T, Sako N, Azuma S, Bai WZ, Wakisaka S (1992) $\mathrm{C}$-fos expression in the rat brain after intraperitoneal injection of lithium chloride. NeuroReport 3:1049-1052.

Yoshimura R, Kiyama H, Kimura T, Araki T, Maeno H, Tanizawa O, Tohyama M (1993) Localization of oxytocin receptor messenger ribonucleic acid in the rat brain. Endocrinology 133:1239-1246.

Zhang X, Ju G, Le Gal La Salle G (1991) Fos expression in GHBinduced generalized absence epilepsy in the thalamus of the rat. NeuroReport 2:469-472.

Zhang X, Gelowitz DL, Lai CT, Boulton AA, Yu PH (1997a) Gradation of kainic acid-elicited rat limbic seizures and expression of hippocampal heat shock protein-70. Eur J Neurosci 9:760-769.

Zhang X, Le Gal La Salle G, Ridoux V, Yu PH, Ju G (1997b) Prevention of kainic acid-induced limbic seizures and Fos expression by GABA-A receptor agonist muscimol. Eur J Neurosci 9:29-40.

Zhang X, Hannesson DK, Saucier DM, Wallace AE, Howland J, Corcoran ME (2001) Susceptibility to kindling and neuronal connections of the anterior claustrum. J Neurosci 21:3674-3687. 